\title{
Rock typing of coquinas from the Morro do Chaves Formation.
}

\author{
Lima, M.C.O. ${ }^{1}$; Martins, L.P. ${ }^{1}$; Rios, E.H. ${ }^{1}$; Boyd, A.; Pontedeiro, E.M.B.D. ${ }^{1}$; Hoerlle, F. ${ }^{1}$; Lipovetsky, T. ${ }^{1}$; Neto, A.O. ${ }^{2}$; Mendes, \\ M.2; Borghi, L.F.2; Couto, P. ${ }^{2}$ \\ 1 - Programa de Engenharia Civil, COPPE/Universidade Federal do Rio de Janeiro \\ 2 - Departamento de Geologia/Universidade Federal do Rio de Janeiro
}

Copyright 2019, SBGf - Sociedade Brasileira de Geofísica

This paper was prepared for presentation during the $16^{\text {th }}$ International Congress of the Brazilian Geophysical Society held in Rio de Janeiro, Brazil, 19-22 August 2019.

Contents of this paper were reviewed by the Technical Committee of the $16^{\text {th }}$ International Congress of the Brazilian Geophysical Society and do not necessarily represent any position of the SBGf, its officers or members. Electronic reproduction or storage of any part of this paper for commercial purposes without the written consent of the Brazilian Geophysical Society is prohibited.

\begin{abstract}
Accurate determination of rock types is essential for the characterization of a reservoir. Rock typing can be an arduous task due to high variation in the pore geometry and a lack of correlation between pore body and pore throat sizes, among other factors. In this work, rock types were determined from permeability bands in coquinas of the Morro do Chaves Formation in Brazil, considered to be close analogues of some Pre-salt reservoirs. The rocks were described using thin sections, while their similarities were confirmed using nuclear magnetic resonance. Results indicated characteristic patterns in terms of their $T_{2}$ distributions. Samples within the same rock type showed similar distribution curves, with the advantage of allowing direct measurements without more complex analyses to characterize the rock types.
\end{abstract}

\section{Introduction}

Rock typing is a critical factor in reservoir characterization by driving the accuracy of reservoir simulations. The identification of petrophysical rock types is especially difficult because of their highly variable pore geometry, a lack of correlation between pore body and pore throat size, and thus between porosity and permeability. It also causes difficulty in establishing a link between small scale pore properties and large scale reservoir properties. Establishing a link between a petrophysical view of the reservoir and the geologic view is hence not trivial. (Skalinski, et al. 2009).

When a reservoir is composed of carbonate rocks, this determination is even more important. Due to their mineralogy, carbonate rocks are more susceptible to diagenetic processes, leading to far more variations in porosity and permeability (Martins et al, 2018).

This study uses coquina rock samples from the Morro do Chaves Formation at the Sergipe-Alagoas Basin in Northeast Brazil. Rocks in this formation are composed of bioclastics, the majority of which are lacustrine bi-valves, modified by transport and diagenesis, resulting in complex pore systems (Hoerlle et al., 2018). The Morro do Chaves Formation can be considered to be a reasonable analogue of some Pre-salt carbonate formations in the Santos and Campos basins, offshore
Brazil, and are similar in age, ranging from Late Barremian to early Aptian (Borghi et al, 2013).

As reported by Corbett et al. (2016), coquinas from the Morro do Chaves Formation have a diagenetic history that can result in dramatic changes in permeability with only slight changes in porosity. This requires the development of a new rock typing approach that simplifies the estimation of flow properties from petrophysical observations.

To aid in the petrophysical characterization of the samples, nuclear magnetic resonance (NMR) techniques were used due to its great power in the investigation of the physical properties of the materials. Often used in the petroleum industry, NMR characterizes reservoirs through laboratory measurements, in addition to using well logging tools (Rios et al., 2010).

An NMR signal is acquired by aligning the spins of ${ }^{1} \mathrm{H}$, contained in the saturating fluid of the samples and induced by a constant magnetic field $\left(B_{0}\right)$. An oscillating magnetic field $\left(B_{1}\right)$ is then applied, perpendicular to $B_{0}$, in order to unbalance the system. After suspension of the $B_{1}$ field, the spins return to their equilibrium position; this return is called nuclear magnetic relaxation, being modelled by exponential decays (Hoerlle et al., 2018). These decays are reversed through mathematical calculations (Laplace inverse transforms) to generate distributions curves. According to Coates (1999), these distributions can be related to size distributions of porosity, the total porosity of the sample and the type of fluid saturating the sample. If only one type of fluid is present, the decay rates directly indicate the pore size since $T_{2}$ is determined by the amount of spin interactions with the pore wall. Therefore, signals with long $T_{2}$ signals can be assigned to large pores, while short $T_{2}$ signals are indicative of small pores (Westphal et al., 2005).

In this work we determine the rock types based on clusters developed from permeability bands. NMR techniques are also applied to confirm similarities between the groups through the $T_{2}$ distribution patterns (Rios et al., 2010). Thin sections were used to aid the classification of rocks, together with descriptions of the pore types and their two-dimensional arrangements.

\section{Method}

In this research project, 16 coquina core samples were obtained from the 2-SMC-02-AL well bore $\left(9^{\circ} 45^{\prime} 29.05^{\prime \prime} \mathrm{S}\right.$ ( $36^{\circ}$ 9'10.65" W) at the CIMPOR Mine, a former Atol Quarry owned by Intercement, in São Miguel de Alagoas (AL). The samples, measuring 1 inch in diameter and 1.5 inch in length, were first cleaned to remove the fluids and 
any impurities present in the pore systems. For this we used Soxhlet extraction with toluene to remove hydrocarbons and methanol to extract the salts. After cleaning, the samples were oven dried at $80{ }^{\circ} \mathrm{C}$ for 12 hours.

After drying, routine core analyses (RCALs) were perform for measuring poroperm properties We used UltraPore300 for the gas porosity and UltraPerm-600 for the gas permeability (both from Core Laboratories) at a confining pressure of 500 psi. The measurements were performed by Solintec, a local core analysis company. After measuring porosity and permeability, the cores were saturated with brine containing 30,000 ppm KCL. Afterwards, the NMR $T_{2}$ distributions were measured at the Laboratory for Applications of NMR and Petrophysics at Fluminense Federal University (UFF-LAR) using GeoSpec2, a $2 \mathrm{MHz}$ lab NMR machine made by Oxford Instruments.

\section{Results}

The main results from the core analysis (RCA) are shown in Table 1. The results were used to construct the porosity-versus-permeability cross-plot shown in Figure 1. Notice the variations in porosity from $4.1 \%$ to $18.8 \%$ and the wide range in permeability from 0.045 to $556 \mathrm{mD}$. The NMR porosity compared well with gas porosimetry results, which indicates that the samples were fully saturated with brine.

\section{Table 1 - RCAL and NMR types information.}

\begin{tabular}{c|c|c|c|c|c|}
$\begin{array}{c}\text { Sample } \\
\text { codes }\end{array}$ & $\begin{array}{c}\phi_{\text {gas }} \\
\mathbf{( \% )}\end{array}$ & $\begin{array}{c}\mathbf{K}_{\text {gas }} \\
(\mathbf{m D})\end{array}$ & $\begin{array}{c}\phi \text { NMR } \\
\mathbf{( \% )}\end{array}$ & $\begin{array}{c}\mathbf{T}_{\mathbf{2 L M}} \\
(\mathbf{m s})\end{array}$ & $\begin{array}{c}\text { Rock } \\
\text { types }\end{array}$ \\
\hline $\mathbf{1 4 6 . 2 5}$ & 4.10 & 0.045 & 4.40 & 11.507 & RT1 \\
\hline $\mathbf{1 4 8 . 0 0}$ & 6.09 & 0.162 & 6.20 & 83.046 & RT1 \\
\hline $\mathbf{1 6 9 . 4 5}$ & 7.74 & 0.166 & 8.00 & 17.659 & RT1 \\
\hline $\mathbf{8 8 . 0 0}$ & 8.70 & 5.21 & 9.00 & 133.049 & RT2 \\
\hline $\mathbf{1 2 2 . 4 5}$ & 12.23 & 5.65 & 12.10 & 75.427 & RT2 \\
\hline $\mathbf{1 7 3 . 5 0}$ & 10.79 & 5.77 & 11.00 & 102.516 & RT2 \\
\hline $\mathbf{1 7 6 . 8 5}$ & 9.84 & 1.73 & 9.100 & 98.663 & RT2 \\
\hline $\mathbf{1 2 6 . 0 5}$ & 11.54 & 13.01 & 11.20 & 225.055 & RT3 \\
\hline $\mathbf{1 2 8 . 0 5}$ & 12.08 & 22.10 & 13.00 & 145.096 & RT3 \\
\hline $\mathbf{1 5 4 . 2 0}$ & 16.59 & 77.17 & 16.20 & 390.126 & RT3 \\
\hline $\mathbf{1 8 4 . 9 5}$ & 11.06 & 63.65 & 11.20 & 285.174 & RT3 \\
\hline $\mathbf{8 3 . 0 5}$ & 18.59 & 556.36 & 17.70 & 484.410 & RT4 \\
\hline $\mathbf{1 0 0 . 7 0}$ & 16.26 & 227.73 & 15.90 & 458.550 & RT4 \\
\hline $\mathbf{1 8 9 . 4 0}$ & 15.10 & 273.66 & 15.20 & 463.135 & RT4 \\
\hline $\mathbf{1 0 2 . 5 5}$ & 18.81 & 174.08 & 18.10 & 310.927 & RT5 \\
\hline $\mathbf{1 6 2 . 5 0}$ & 17.52 & 121.98 & 17.60 & 311.066 & RT5 \\
\hline
\end{tabular}

The porosity-permeability scatter plot in Figure 1 was also useful for identifying the 5 main rock types shown as colour coded clusters, with rock types 1-4 showing a trend of increasing permeability with porosity, while rock type 5 indicates a lower permeability than rock type 4 , but a higher porosity.

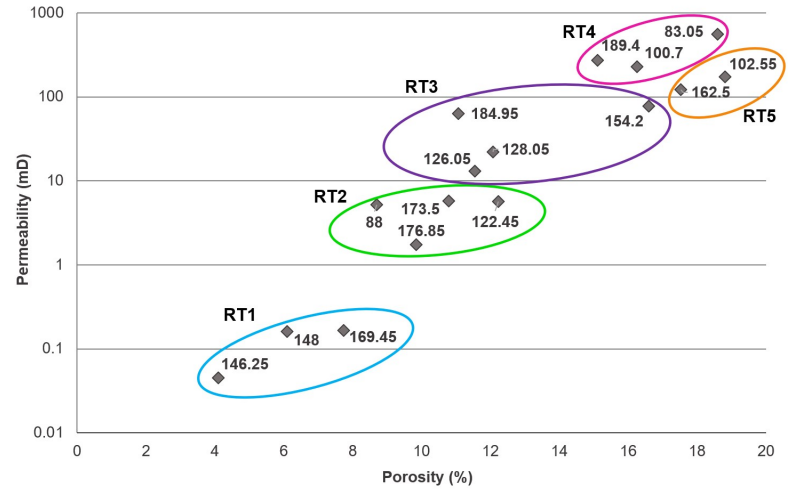

Figure 1 - Cross-plot showing porosity versus permeability for different rock types.

As indicated in Figure 1, the samples were separated into rock types (RT) according to permeability bands. The RT1 samples had lower permeabilities, from 0.045 to 0.166 $\mathrm{mD}$; the RT2 samples varied from 1.73 to $5.77 \mathrm{mD}$; the RT3 samples varied from 13.01 to $77.17 \mathrm{mD}$; the RT4 samples from 227.73 to $649.91 \mathrm{mD}$; while the RT5 has permeabilities varying in value from 121.98 to $232.93 \mathrm{mD}$.

The similarity among the samples of each group was confirmed based on the shape of the $T_{2}$ distributions and their logarithmic mean values $\mathrm{T}_{2 \mathrm{LM}}$ (Table 1). The classification of pores was based on qualitative partitioning of the $\mathrm{T}_{2}$ distributions as used by Silva et al. (2015). The heterogeneity of the samples is well evidenced by the variation of the pore families within the set, thus reinforcing the $T_{2}$ partitioning ideas presented by Silva (2015): $\mathrm{T}_{2}$ up to $1 \mathrm{~ms}$ is considered to be micropores; between 1 and $10 \mathrm{~ms}$ is a transition region between micro and mesopores; from 10 to $100 \mathrm{~ms}$ consists of mesopores; from 100 to $1000 \mathrm{~ms}$ is a transition zone between meso and macropores, and over $1000 \mathrm{~ms}$ are macropores. Figures 2a, 3a, 4a, 5a and 6a show the distributions of $T_{2}$ for rock types RT1, RT2, RT3, RT4 and RT5, respectively. 
a)
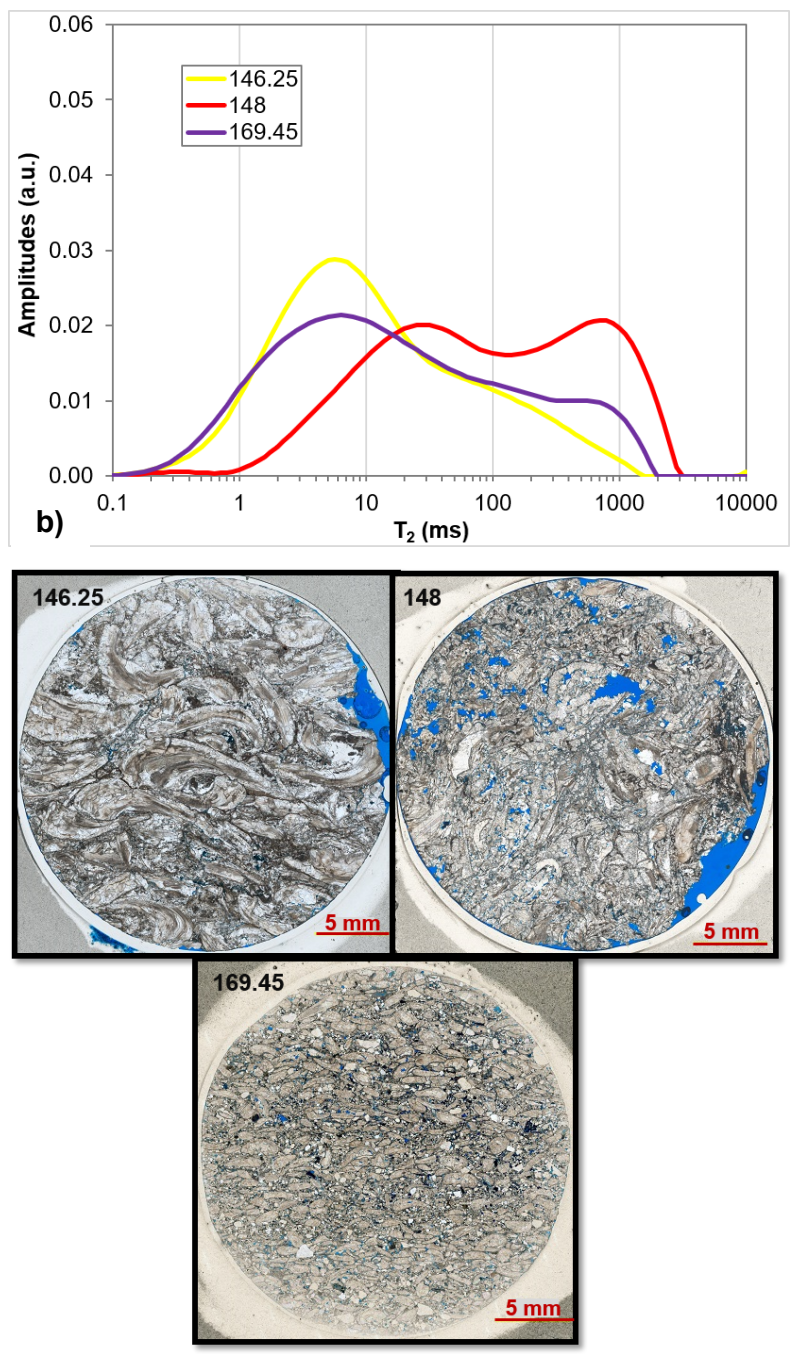

Figure 2 - a) $T_{2}$ distribution and b) thin sections of the RT1 samples.

In Figure 2a variations in pore sizes can be observed according to their transverse relaxation times. The set presents bimodal samples, with pores that vary between micro- and macro-pores according to the partitioning used by Silva et al. (2015). The distributions have low amplitudes corresponding to low porosities and low permeabilities. $T_{2 L M}$ range from 11 to $83 \mathrm{~ms}$, with porosities between 4.1 and $7.79 \%$ and permeabilities between 0.045 and $0.166 \mathrm{mD}$.
Figure $2 b$, shows thin sections of RT1. The rocks were classified as calcarenites composed of whole and fragmented shells, which are densely packed, with predominance of moldic and intraparticle pores. Note the scarcity of pores in the images, especially of sample 146.25 , due to intense cementation resulting in a porous system that is more closed.

a)
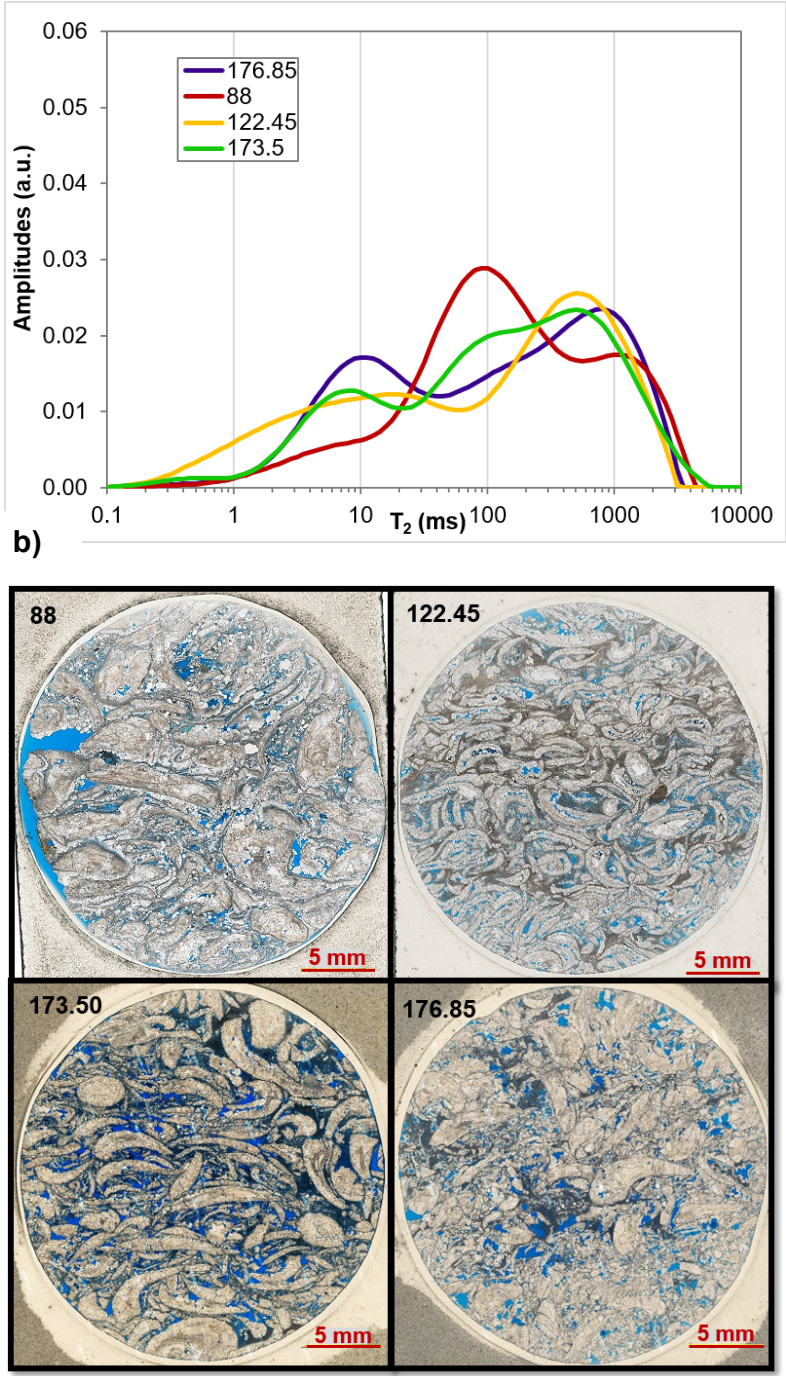

Figure $3-$ a) $T_{2}$ distributions and b) thin sections of the RT2 samples.

Figure 3a shows curves of the samples belonging to RT2. The set consists of bimodal samples, with the pore size varying between micro-and macro-pores, and with $\mathrm{T}_{2 \mathrm{LM}}$ between 75 and $133 \mathrm{~ms}$, porosity between 8.70 and $12.23 \%$ and permeability from 1.73 to $5.77 \mathrm{mD}$. Although the samples of RT1 and RT2 presented bimodal distributions with large variations in their pore size, it is worth mentioning that RT2 has a higher average $T_{2}$, which is consistent with the increase in permeability.

In the descriptions of the thin sections (Fig. 3b) we observed that the samples are classified as calcarenites 
and calcirudites composed of whole and fragmented shells, densely to loosely packed. The pores, for the most part, are interparticle, intraparticle and vugs. The pore system of these samples ws different as compared to RT2, with a higher presence of visible pores. Due to compaction, these samples presented low connectivity, thus impacting the permeability.

a)
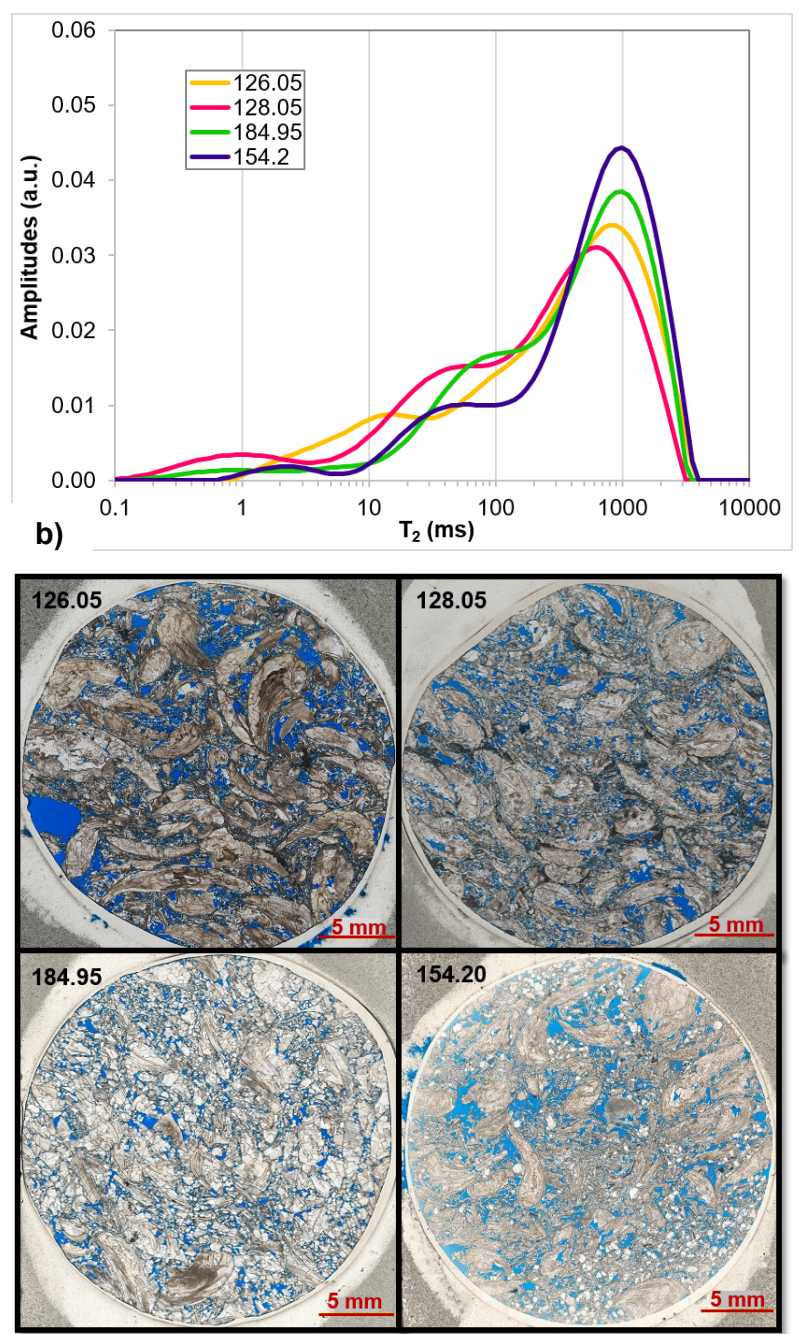

Figure 4 - a) $T_{2}$ distribution curves and b) thin sections of the RT3 samples.

In Figure $4 a$, the $\mathrm{T}_{2}$ distribution of the RT3 samples are composed of pores varying from micro- to macro-pores. They have $T_{2 L M}$ values between 225 and $390 \mathrm{~ms}$, porosities between 11.60 and $16.59 \%$ and permeabilities between 13.01 and $77.17 \mathrm{mD}$. Again, an increase in T2LM values correlates with an increase in permeability.
The thin sections of this rock type (Fig.4b) were described as calcirudites and calcarenites, composed of whole and fragmented shells, densely packed. Most of the pores were classified as intraparticular, moldic and intercrystalline. Higher amounts of pores were visible and more connected, consistent with an increase in permeability as compared with RT1 and RT2.

a)
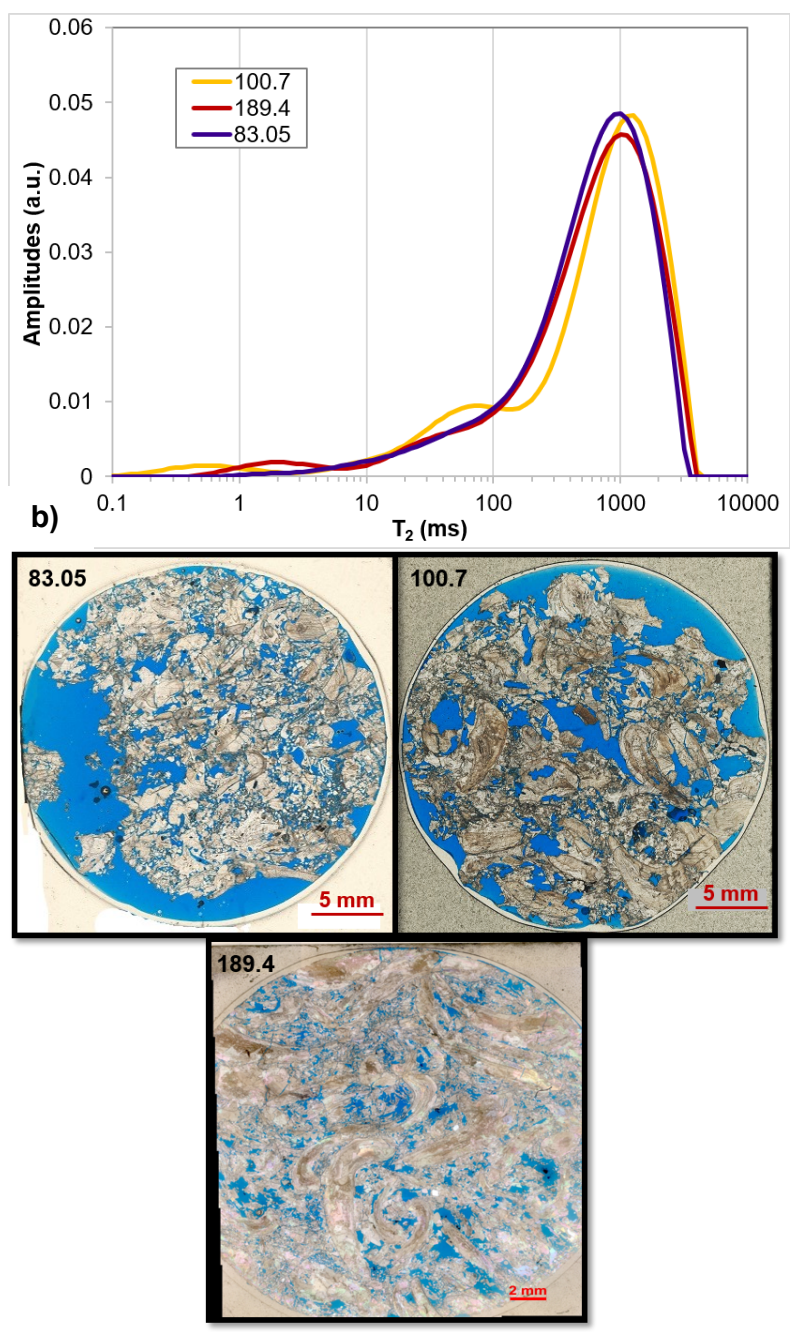

Figure $5-a) T_{2}$ distributions and $b$ ) thin sections of the RT4 samples.

Distributions of the RT4 samples are shown in Figure 5a. Note the predominance of pores above the hybrid region of meso- and macro-pores, with no presence of micropores. They have higher $\mathrm{T}_{2 \mathrm{LM}}$ values, ranging from 458 to $484 \mathrm{~ms}$, porosities ranging from 15.1 to $18.59 \%$, and relatively high permeabilities, from 227.73 to 556.36 $\mathrm{mD}$.

The samples (Fig. 5b) were classified as calcirudites and calcarenites composed of whole and fragmented shells, densely packed. The pores were represented by vugs and a majority of intraparticles. It is evident that the significant increase of visible pores, especially the pore throats (which are larger than those of RT1, RT2 and $\mathrm{RT} 3$ ) results in higher permeabilities, as is the case for 
sample 83.05 having a permeability of $556.36 \mathrm{mD}$. a)
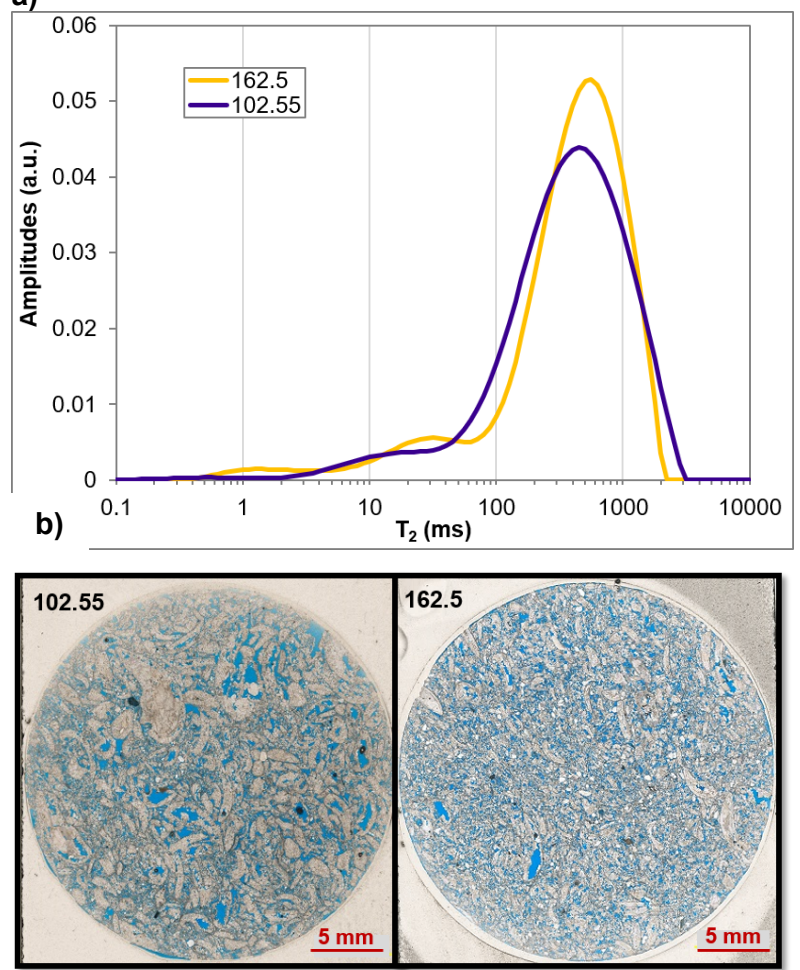

Figure $6-$ a) $T_{2}$ distribution and b) thin sections of the RT5 samples.

As can be seen in Figure 6a, the RT5 samples showed $T_{2}$ distribution in the meso- and macro-pore range, while no microporosities were observed. Samples 102.55 and 162.5 had $\mathrm{T}_{2 \mathrm{LM}}$ values of 310.9 and $311.06 \mathrm{~ms}$, respectively; porosities of 18.81 and $17.52 \%$, respectively; and permeability values of 174.08 and $121.95 \mathrm{mD}$, respectively. Samples of this rock type were separated from RT4 due to the decrease of $\mathrm{T}_{2 \mathrm{LM}}$ and the decrease of the permeability, following the pattern found for the division of the clusters.

The samples of this group (Fig. 6b) were classified as calcirrudite and calcarenite composed of whole and fragmented shells, densely packed. The pores of these samples were for the most part classified as intraparticular and moldic. Figure $6 \mathrm{~b}$ shows the differences in pore morphology of groups RT4 and RT5: pore sizes as well as their shapes can be observed. They show smaller sizes than RT4 samples (Fig. 5) and greater packaging, in addition to narrower pore throats, leading to a slight decrease in permeability. These results confirm that the samples do not have the same petrophysical characteristics, and hence that the RT4 samples must be separated.

\section{Conclusions}

This research concerned rock typing of samples taken from a core drilled at the Morro do Chaves Formation. Using routine core analysis data, a porosity versus permeability cross-plot was constructed and the clusters were elaborated based on the permeability bands.
The rocks were described by analysing thin sections, which showed the preservation of shells, packaging and different type of pores. Since the samples showed large heterogeneities, the recognition of similarities between them became complex, being insufficient for their separation into different groups. However, the identification of the pores and their connections was advantageous, such as in the case of the RT4 samples, which had narrower pores as compared to RT5, resulting in lower permeabilities.

The similarities between the samples within a specific rock type were confirmed by NMR measurements. By observing curves of the $T_{2}$ relaxation times, which reflect the distributions of the pore size families, it was possible to observe similar curve shapes. Based on the assumption that logarithmic mean relaxation times are associated with mean pore size, we observed that the $T_{2 L M}$ increase is directly related to permeability increased.

\section{Acknowledgments}

This research was carried out in association with the ongoing R\&D projects registered as ANP 19027-2, "Desenvolvimento de infraestrutura para pesquisa $e$ desenvolvimento em recuperação avançada de óleo EOR no Brasil" (UFRJ/Shell Brasil/ ANP) setting-up a advanced EOR Lab facility for R\&D in Brasil, and ANP 20163-2, "Análise experimental da recuperação de petróleo para as rochas carbonáticas do pré-sal brasileiro através da injeção alternada de $\mathrm{CO} 2$ e água", both sponsored by Shell Brasil under the ANP R\&D levy as "Compromisso de Investimentos com Pesquisa e Desenvolvimento". This research was also carried out with the support of project ANP 18029-9 "Projeto de correlação petrofísica poço $x$ perfil" sponsored by Petrobras under the ANP R\&D levy "Compromisso de Investimentos com Pesquisa e Desenvolvimento". This study was financed in part by the Coordenação de Aperfeiçoamento de Pessoal de Nível Superior- Brasil (CAPES) - Finance Code 001, and carried out with the support of CNPq, National Council of Scientific and Technological Development - Brazil. We acknowledge Professor Leonardo Borghi from Federal University of Rio de Janeiro and the Sedimentary Geology Laboratory (LAGESED/UFRJ) for the concession of the samples of the SACL project - Sedimentary geological analysis of Cretaceous carbonate successions in a Brazilian sedimentary basin (ANP authorization n.551 / 2012, BG E \& amp; P Brazil project BG-04, COPPETEC Foundation project IGEO-15.981). We acknowledge the Professor Rodrigo Bagueira (UFF-LAR) for the aid the saturation of the samples and use of the NMR equipment. Also, thanks to Prof. Martinus Theodorus Van Genuchten for the colaborative suggestions and to the research teams of LRAP/COPPE/UFRJ and LAGESED/UFRJ.

\section{References}

Borghi, L. \& Corbett, P. W. M. Lacustrine Carbonates For the Purpose of Reservoir Characterization Are They Different? Offshore Technology Conference, 2013;

Corbett, P.W.M.; Estrella, R.; Shoier, A.; Morales, A.; Borghi, L. Integration of Cretaceous Morro do Chaves rock properties (NE Brazil) with the Holocene Hamelin 
Coquina architecture (Shark Bay, Western Australia) to model effective permeability. Petroleum Geoscience, v.22, pp. 105-122, 2016;

Hoerlle, F.; Rios, E.H.; Silva, W.G.A.L.; Pontedeiro, E.M.B.D; Lima, M.C.O.; Corbett, P.W.M.; Alves, J.L.D.; Couto, P.; Nuclear magnetic resonance to characterize the pore system of coquinas from Morro do Chaves Formation, Sergipe-Alagoas basin, Brazil. Revista Brasileira de Geofísica, n.36, v. 3, p.1-8, 2018;

Martins, L.; Lima, M., M.; Orlandi, A.; Mendes, M.; Borghi, L. F.; Couto, P. Universidade Federal do Rio de Janeiro (UFRJ) Utilização da técnica de Ressonância Magnética Nuclear (RMN) para caracterização petrofísica das coquinas da Formação Morro do Chaves, Bacia de Sergipe-Alagoas. SBGF, VIII Simpósio Brasileiro de Geofísica, 2018;

Rios, E.H.; Stael, G.C.; Ramos, P. F. O.; Azeredo; R.B.V. Caracterização petrofísica de rochas reservatórios por Ressonância Magnética Nuclear. SBGF, IV Simpósio Brasileiro de Geofísica, 2010;

Silva, P.N; Gonçalves, E.C.; Rios, E.H.; Muhammad, A..; Moss, A.; Pritchard, T.; Glassborow, B.; Plastino, A.; Azeredo, R.B.V. Automatic classification of carbonate rocks permeability from ${ }^{1} \mathrm{H}$ NMR relaxation data. Expert systems with Applications, v.42, pp. 4299-4309, 2015;

Skalinski, M.; Kenter, J.; Jenkins, S. Rock type definition and pore type classification of a carbonate plataform, Tenciz Field, Republic of Kazakhstan. SPWLA, 50th Annual Logging Symposium, Texas, June, 2009;

Westphal, H.; Surholt, I; Kiesl, C.; Thern, H.F.; Kruspe, T. NMR measurements in carbonate rocks: problems and an approach to a solution. Pure and applied geophysics, v.162, pp. 549-570, 2005. 